\title{
Arte doméstica e imagem da nação: um olhar sobre os museus-casa de Rui Barbosa e de Benjamin Constant
}

\author{
Marize Malta \\ Escola de Belas Artes \\ Universidade Federal do Rio de Janeiro
}

\begin{abstract}
RESUMO: Muitos objetos cotidianos e domésticos que pertenceram a indivíduos do passado, ao serem musealizados, desenvolveram uma simbologia visual para futuros cidadãos brasileiros. A casa com sua decoração de interior, móveis, objetos, ou seja, com toda a sua arte doméstica, predispunha-se a ter papel significativo no projeto nacional de ordem e progresso, cumprindo um papel primordial de representante da pátria que, na sua forma institucionalizada e preservada se transformaria em museu-casa. A partir da análise das configurações dos museus-casa de Rui Barbosa e de Benjamin Constant, pretende-se lançar luz elucidar acerca da tipologia museu-casa e refletir sobre questões como categorias artísticas, reconstituições de ambientes, domesticidade e publicidade, relação de objetos e pessoas, imagens da nação.
\end{abstract}

PALAVRAS-CHAVE: arte doméstica, museus-casa, imagem da nação

ABSTRACT: Many everyday and domestic objects which belonged to individuals in the past developed a visual symbology for future Brazilian citizens when they became museum pieces. The house with its interior decoration, furniture and objects, that is with all its domestic art, predisposed a significant role in the national project of order and progress thus playing an important role in representing the country, when in an institutionalized and preserved form it became a house museum. By analysing the configuration of Rui Barbosa and Benjamin Constant's house museums the text aims to shed light on house museum typology and reflect on issues such as artistic categories, interior decoration reconstructions, domesticity and publicity, the relationship between objects and people, images of the nation.

KEYWORDS: domestic art, house museums, the nation's image

Grande parte dos acervos existentes nos museus do Rio de Janeiro refere-se a objetos e obras produzidos principalmente no século XIX e início do século XX, doados, em sua maioria, por particulares e colecionadores (Knauss, 2001: 23-44), membros da boa sociedade residente no Rio de Janeiro, de modo a garantir a perenidade de determinada imagem de si próprios, mas que acabaram por se transformar em representantes da cultura material de toda a nação. As peças oitocentistas ${ }^{1}$ seriam as que quantitativamente mais corresponderiam ao desejo de memória preservada da nação. Não por acaso, boa parcela desses objetos está situada em museus cujos imóveis foram construídos no século XIX, museus motivados, por vezes, pela criação de um lugar de memória (Nora, 1984) e

\footnotetext{
1 Tomamos como premissa o longo século XIX, que abarca fins do século XVIII até fins da República Velha.
} 
que se constituíram em uma espécie de panteão de heróis nacionais lidos por meio dos seus objetos pessoais e dos espaços contemporâneos a eles.

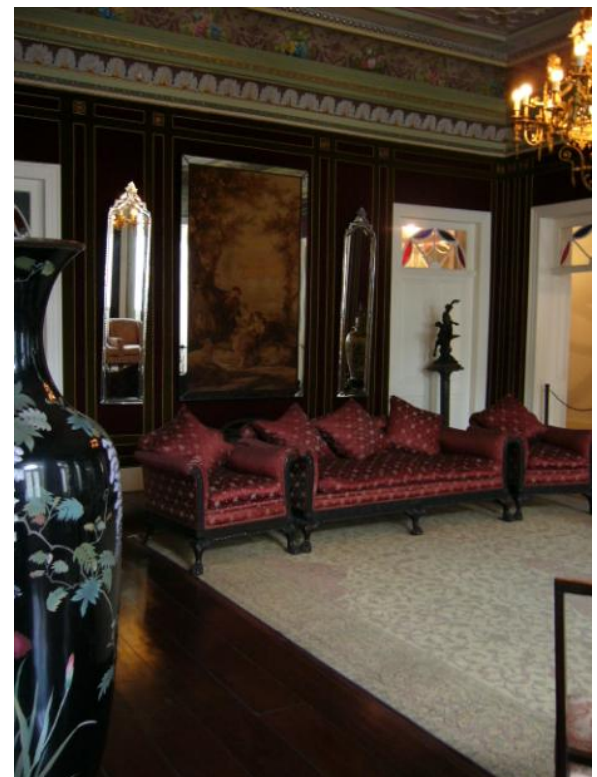

Fig.1. Salão nobre com paredes forradas em veludo, teto em estuque policromado, piso em tábua corrida sobreposto com tapete de decoração floral, espelhos bisotados, tapeçaria Gobelin, conjunto de estofado em cetim lavrado, lustre de bronze dourado, jarrão japonês e escultura em bronze sobre pedestal de mármore. Museu Casa de Rui Barbosa. Foto Marize Malta

Muitos objetos cotidianos e domésticos que pertenceram a indivíduos do passado, ao serem institucionalizados e exibidos, desenvolveram uma simbologia visual para os futuros cidadãos brasileiros que, pela observação das peças expostas publicamente, corroboravam um desejo de construção de uma memória social (Halbwachs, 1990), válida para toda uma coletividade. Nesse processo, as coisas materiais auxiliavam a desenvolver formas não convencionais de comunicação e de exercícios de poder. Assim, reforçava-se a ideia de que objetos possuíam um papel importante na vida das pessoas² e na construção da memória da nação.

Esses artefatos compunham as mais variadas categorias e conforme classificações que recebiam eram predestinados a certos tipos de museu: de história; artes visuais; antropologia e etnografia; arqueologia ${ }^{3}$. A divisão levou a que certos grupos de artefatos só fossem acolhidos se condizentes com a natureza da instituição. 0 procedimento realçou

\footnotetext{
2 Alguns trabalhos, nos últimos anos, têm se debruçado sobre a relação dos objetos com as pessoas e reavaliado sua importância para a construção da autoimagem de seus proprietários (Cohen, 2006 e Jones, 2007).

${ }^{3}$ Atualmente está vigente a seguinte tipologia de coleções: antropologia e etnografia; arqueologia, artes visuais (inclui as artes aplicadas); ciências naturais e história natural, ciência e tecnologia; história; imagem e som; virtual; biblioteconômico; documental; arquivístico (GUIA DOS MUSEUS BRASILEIROS, 2011: 19-20).
} 
as compartimentações disciplinares do conhecimento, os conceitos dominantes da boa arte e do bom objeto, dispersando o conjunto de coisas com que se conviviam e que foi amealhado ao longo de uma vida. Quadros e esculturas iriam para museus de belas artes, borboletas para o museu de história natural, vasos marajoaras para museus de antropologia, xícaras e jarrinhas para o museu histórico. Dessa maneira, todas as peças que estiveram reunidas, algum dia, dispersaram-se e cada subgrupo de artefatos procurou dar conta de uma determinada identidade, fragmentando a relação objeto e memória e personalidade que, de forma ampla, complexa e dinâmica, dava-se na cotidianidade dos espaços de moradia.

Fig.2. Canto da sala de entrada com paredes em pintura decorativa pompeiana, piso em tábua corrida, bergère em couro capitonê, abajur de pé. Museu Casa de Rui Barbosa. Foto Marize Malta

Oscar Wilde, em 1890, afirmava que a arte mais francamente decorativa era a arte com que se vivia (2002). Wilde falava, portanto, de uma arte próxima, ao alcance das mãos, corriqueira, uma arte banal, uma arte doméstica. Os objetos de casa se colocavam como referências próximas, frutos de uma cultura material compartilhada nas práticas do vivido. Esses objetos, bem como o espaço que os circundava e o modo como estavam dispostos, foram, no século XIX, alvo de um projeto social que delegava ao lar a missão de educar os futuros cidadãos, transpondo para a arte doméstica os primeiros ensinamentos estéticos que iriam conformar espíritos civilizados e refinados (Malta, 2011a). A casa com toda a sua decoração, formada por padrões, cores, materiais e formas diversas, predispunha-se a ter papel significativo no projeto nacional de ordem e progresso, cumprindo uma função 
primordial de representante da pátria que, na sua forma institucionalizada e preservada se transformaria em museu-casa.

Por outro lado, os museus, segundo Gaskel (1992: 235-271), seriam repositórios de dois tipos de objetos: de peças obsoletas que representam um determinado ofício, um acontecimento, um comportamento (museus históricos, museus de tradição popular, etc.) ou de coisas de valor estético (museus de belas artes). Nesse universo, os museus-casa se estabelecem em terreno delicado e instável porque lidam com tipos de objetos que podem ser uma coisa e outra ou nenhuma coisa nem outra: podem ser arte em casa ou uma casa 'com arte' ou um museu em casa, dificultando aproximações para o estudo de seu acervo.

A maioria dos museus-casa, no Brasil, relaciona-se ao século XIX, reforçando a ideia de que a casa, a domesticidade e a decoração existiriam como manifestação consciente somente nos oitocentos. Se nos valermos da quantidade de casas históricas preservadas, cujos acervos correspondem a épocas anteriores ou posteriores ao século XIX, elas estão em desvantagem, predominando aquelas que correspondem ao período imperial e início da República.

No Rio de Janeiro, frente ao papel desempenhado pela cidade para a história política do país, há bons exemplos de casas históricas, muitas delas, musealizadas. Porém, poucas possuem acervos materiais de época, preservam os ambientes interiores do XIX e correspondem a escolhas de uma única família, de modo que se tenha um universo controlado para uma análise complexa da arte doméstica oitocentista. Cumprindo esses requisitos, encontramos os museus-casa de Rui Barbosa ${ }^{4}$ e de Benjamin Constant ${ }^{5}$, cujas decorações domésticas foram até hoje pouco exploradas pelas histórias - social, cultural e da arte.

O museu-casa de Rui Barbosa situa-se na rua São Clemente, 134, no bairro de Botafogo, e o museu-casa de Benjamin Constant está na rua Monte Alegre, 255, em Santa Teresa. Ambas as instituições são federais, submetidas ao Instituto Brasileiro de Museus e recebem visitantes que ainda hoje se surpreendem com aqueles interiores cuidadosamente montados, com cores, móveis e objetos tão diferentes dos usados hoje em dia.

\footnotetext{
${ }^{4}$ Para maiores informações, visite o site www.casaruibarbosa.gov.br

5 Para maiores informações, visite o blog http://www.museubenjaminconstant.blogspot.com/
} 
Ao adentrarmos nesses museus, temos a sensação de que atravessamos um portal do tempo. Em seus ambientes, encontramos vestígios de outra época, observamos como decoravam as casas, que móveis e objetos foram escolhidos, usados e arranjados para satisfazerem necessidades estéticas, operacionais, psicológicas e simbólicas da família que ali viveu. Uma arte doméstica parece se materializar.

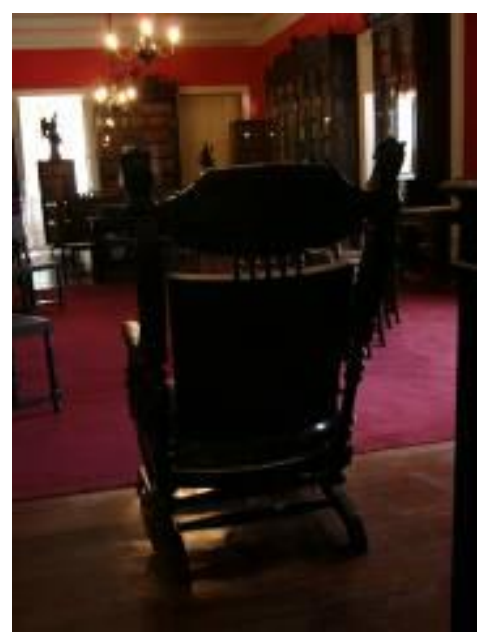

Fig.3. Biblioteca de Rui Barbosa com os altos armários-bibliotecas envidraçados, escrivaninha ao fundo, cadeiras e poltronas em madeira e couro de sola gravado e esculturas em bronze. Museu Casa de Rui Barbosa. Foto Marize Malta

Passeando pelos espaços das casas de Rui Barbosa e de Benjamin Constant não encontramos apenas objetos de estilo, ligados à leitura da tradição da história da arte. 0 valor das peças não está, de imediato, em suas qualidades estéticas. As peças se exibem pelo valor do proprietário para a história nacional, são símbolos de seus gostos e modos de vida. São objetos relíquias, diferentes de peças localizadas em museus de arte e de artes decorativas.

Nos museus de arte houve pouco espaço reservado para os ditos objetos decorativos, pois se acreditou que estariam deslocados, em lugar impróprio. Como não houve nem há no no Brasil museus dirigidos às artes decorativas, os móveis e acessórios oitocentistas foram levados para museus de interesse histórico, desenvolvendo a ideia de que os museus históricos seriam o lugar natural de destino desses objetos. ${ }^{6}$

\footnotetext{
$6 \mathrm{O}$ uso da expressão 'meramente decorativo', no decorrer do século XX, apontou para uma condição do objeto como algo inútil. Paralelamente, aquilo que 'não seria mais necessário' iria para o museu ou viraria coisa de museu. Na sequência desse raciocínio, aquilo que fosse simplesmente decorativo seria predestinado ao museu e um objeto decorativo seria próprio para ser um dia musealizado. Ele já seria potencialmente peça para museu.
} 
Fig.4. Dormitório do casal Maria Augusta e Rui Barbosa, com paredes em papel de parede, janelas com sanefas, cama em latão, genuflexório, cômoda-toalete com bacia e gomil, um par de cadeiras de quarto, crucifixo, arandelas em opalina. Museu Casa de Rui Barbosa. Foto Marize Malta.

O acervo do museu-casa tem valor documental relevante, representa um gosto datado e individualizado de determinada família. A princípio, os objetos não fazem parte do acervo porque um curador os escolheu, mas porque os moradores, segundo convenção, necessidades cotidianas, estilo de vida, oferta da época e gosto, elegeram aqueles objetos. Os acervos, assim, podem nos sugerir como era a dimensão decorativa a partir das práticas do vivido. Pelo menos é o que a museografia nos faz acreditar.

Diferentemente de peças transpostas para museus históricos, caso em que tomam mais facilmente a classificação de semióforos ${ }^{7}$, estamos diante de móveis em seu lugar de idealização, uso e convívio. Sentimos que eles estão em casa. Contudo, ao considerá-los documentos, ao desejarmos melhor compreendê-los e, por meio deles, chegarmos perto das pessoas que os usavam e de seus hábitos cotidianos, alguns incômodos se apresentam.

Quando entramos em um museu-casa, tendemos a colocar nossa própria e única experiência de habitar como ponto de partida para analisar o ambiente doméstico estranho ao nosso tempo. Ficamos curiosos em saber como então moravam os que um dia foram os donos daquelas coisas e transitavam naquele espaço. Somos imbuídos de um forte voyeurismo na medida que temos a sensação de invadir a intimidade de outros. 0 museu, todavia, só permite ao visitante a fantasia do voyeur. A questão é o que permitir ao

\footnotetext{
7 Objetos que não servem para serem usados, mas só para serem expostos ao olhar (Abreu, 1996: 43-44).
} 
voyeur observar, o que ocultar e o que deixar à vista, o que fechar e o que abrir ou, em termos expográficos, o que priorizar apresentar: uma casa antiga, uma coleção de objetos, um acervo histórico ou uma recolha de coisas curiosas, dentre tantas outras possibilidades. Dificilmente encontramos uma museografia que enfatize a pouco explorada arte doméstica.

Fig.5. Copa com piso em ladrilho hidráulico, azulejo a meia altura, bancada com pia sobre base em madeira pintada a óleo, filtro de água, identificador de chamada. Museu Casa de Rui Barbosa. Foto Marize Malta

Normalmente não se contextualiza o uso e a forma dos objetos dispostos. No geral, as legendas, colocadas ao lado de cada objeto (que segue a tradição das obras de arte), traduzem em palavras o que os olhos já observaram. Algumas informações são ampliadas, como data ou fabricação do objeto (Sèvres, Gobelin, Companhia das Índias...). Esse processo induz acreditar que as peças falam por elas mesmas.

Para o visitante, alguns objetos só são entendidos ao se recuperar as práticas sociais com que esses objetos conviviam e serviam. Quando certas práticas não estão mais na ordem do dia, viraram coisas do passado, os objetos relacionados a elas podem parecer estranhos aos olhos do tempo recente. É o caso, por exemplo, das rasteiras cadeiras de costura, das escarradeiras, das peniqueiras, das mesas-trinchantes.

Os espaços, dinâmicos no cotidiano, parecem estatizados nos museus. Preservando inalterados, objetos e arranjos apresentam ideia de aprisionamento do tempo. Esse desejo de tentar suspender a voracidade do tempo passa a impressão de uma fictícia segurança: toda vez que o visitante volta ao museu encontra a peça exatamente no mesmo lugar. Nada mudou. 0 museu reforça a ideia de uma instituição que tem o poder de imunizar o 
desgaste daquilo que está sob seu jugo, de oferecer ampla segurança e que, portanto, é o lugar refratário ao passar do tempo. Quando objetos entram por suas portas parece que foram banhados por um elixir e agraciados com a vida eterna. Da manipulação cotidiana, as peças se estatizaram para serem usadas visualmente.

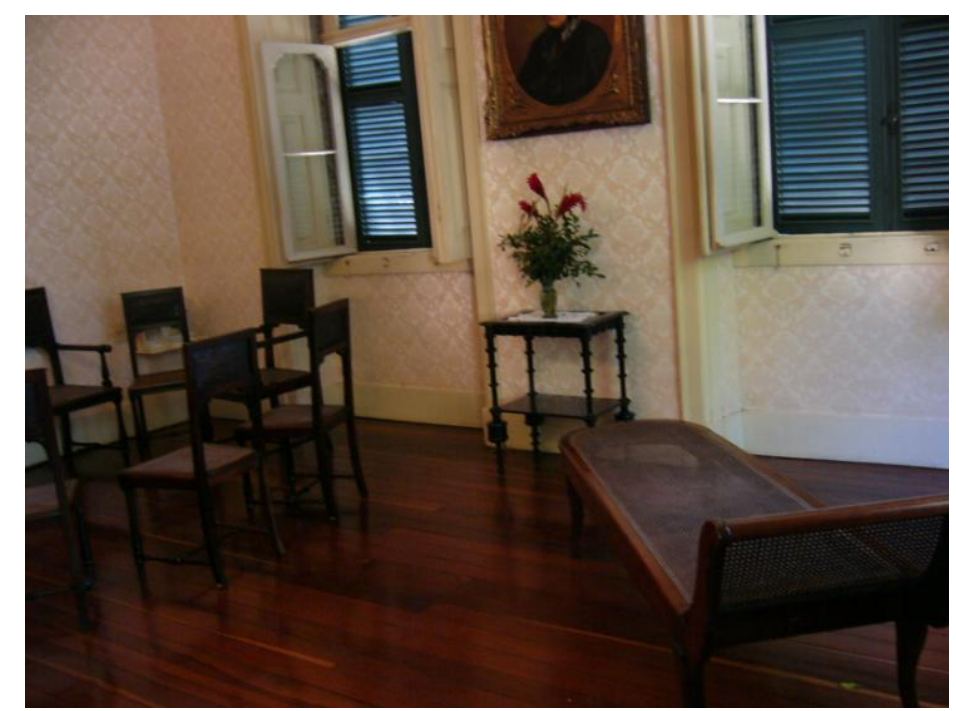

Fig.6. Sala de visitas com paredes forradas em papel, piso em tábua corrida, conjunto de canapé e cadeiras em madeira e couro de sola gravado, mesa e recamier, tela com moldura dourada. Museu Casa de Benjamin Constant. Foto Marize Malta

Ao terminarmos uma visita a museus-casa, saímos convencidos de que assim vivia aquela família. Entretanto, diante da necessidade de segurança dos museus, dificilmente chegamos perto de uma organização cotidiana. As pessoas daquele tempo se foram. Seus pertences, enclausurados em vitrines. Aquilo que era devidamente guardado, posto fora do alcance dos olhos de estranhos, pode ser evidenciado, vir a público. Aquilo que se tinha por hábito deixar à vista, pode ser ocultado em uma reserva técnica. Com essas acomodações, a decoração passa a ser de outro tempo.

Mai uma questão que os museus-casa nos coloca, é que a casa parece sempre estar arrumada para um dia de festa, mesmo que não esteja enfeitada para tal ${ }^{8}$. Tudo parece extremamente arrumado e esperando os convidados. A arrumação, contudo, não foi realizada pelos moradores originais, mas por profissionais que têm como tarefa a

\footnotetext{
${ }^{8}$ Durante os dias de festa, era comum enfeitar a casa com arranjos florais que podiam pender dos tetos, estar fixados em paredes, acompanhar os movimentos das sanefas das cortinas, circundar em festões as mesas, dialogando com buquês e corbeilles assentes em mesas, consoles e pedestais. Além disso, conforme o número de convidados e tipo de cerimônia, o arranjo e o número dos móveis se modificavam, o que levava a encontrar uma ambiência bem diferente daquela comum ao dia a dia.
} 
preservação daqueles espaços e coisas. Tudo é apresentado no seu estado quase novo bem polido, bem lustrado, bem restaurado, como se as coisas fossem imunes ao desgaste. Essa condição nos leva a questões tais como: será que todos os móveis tinham aparência de novo? não existiria uma convivência entre os antigos e gastos objetos com os mais recentes? não haveria momentos de desalinho dos móveis e dos objetos? e ainda, o que hoje é considerado arrumado tinha a mesma disposição no passado? São perguntas que estão relacionadas à preocupação com a autenticidade, valor com que a tradição da história da arte se ocupou, principalmente em relação aos objetos de arte.

Em alguns catálogos de museus, a situação do objeto enquanto coisa célebre acirra-se. Podemos encontrar itens de destaque do acervo vistos isolados, seguindo prática dos estudos de artes decorativas. Raramente observamos estudo do conjunto das peças de determinado cômodo, o papel de cada objeto dentro do conjunto, a forma de arranjo, a hierarquia, a importância para os moradores, como percebiam os objetos e como os usavam, que sentidos lhes atribuíam, etc. Essa dimensão cultural e material das relações dos objetos entre si e do seu convívio com as pessoas é suprimida do público. Não se encontra a arte doméstica.

Os museus, desde sua origem (Chagas, 1997: 177-199), foram predestinados a abrigar a conjunção entre memória e poder. Os móveis, as peças decorativas, a decoração de interiores seriam repositórios de memória e afiançariam a perpetuação da história de homens públicos, como resultado de negociações políticas que escolheram consagrar um ou outro cidadão para simbolizar a história nacional, na sua versão desejada.

Se os museus podem ser fontes para pesquisas históricas “(...) a produção do conhecimento histórico deve ser indissociável do conhecimento (histórico) da produção do documento, no seu sentido mais amplo" (Meneses, 1994: 24). É preciso conhecer os passos da construção da memória de cada decoração-museu. Cada museu teve sua história de formação do acervo, mostrando que a decoração em museu possui tempos diversos e o que se apresenta ao visitante é um somatório de tempos sobrepostos e justapostos.

O museu-casa de Rui Barbosa foi inaugurado em 13 de agosto de 1930 e o museu-casa de Benjamin Constant abriu suas portas em 18 de outubro de 1982, apesar de ambas as casas serem contemporâneas e tratarem de ambientes de fins do século XIX. A casa de Benjamin 
Constant foi a primeira a ser alvo de interesse de preservação pela União, logo após a morte de seu patrono, em 1891, mas só se transformou em museu muitas décadas depois. A recém-fundada República, a partir da sua primeira Constituição, determinava a compra da casa, que permaneceria em usufruto da viúva de Benjamin, Maria Joaquina.

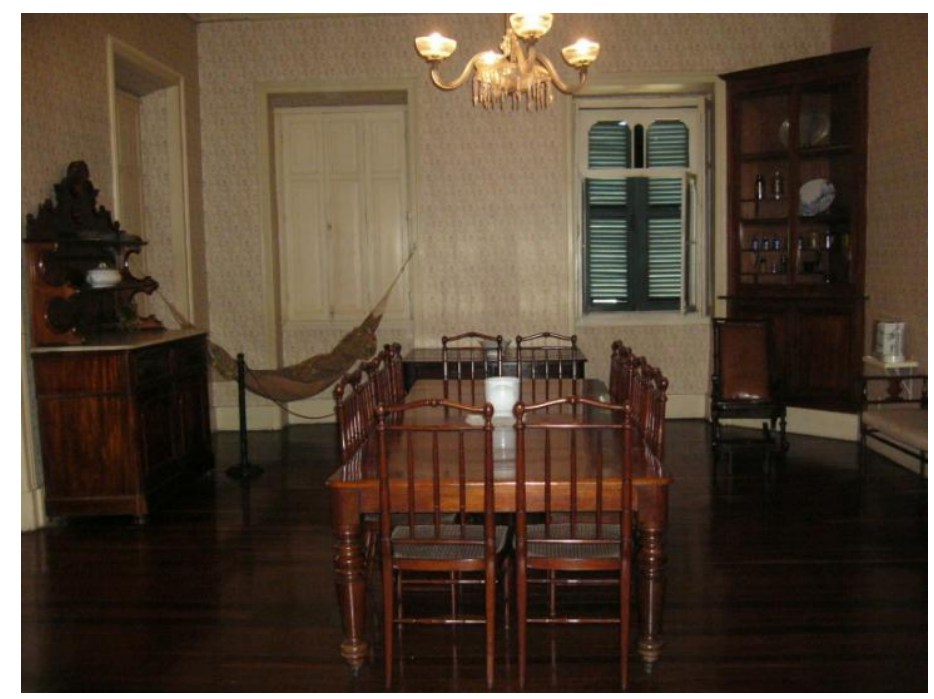

Fig.7. Sala de jantar com paredes forradas em papel, piso em tábua corrida, armário de canto para guardar remédios, bufê, rede, mesa com cadeiras, cadeira de balanço e canapé em madeira e palhinha, lustre em cristal gravado. Museu Casa de Benjamin Constant. Foto Marize Malta

A intenção de transformar a casa de Benjamin Constant em um monumento da República apontava para um projeto de construção de novos heróis, fazendo com que na primeira Constituição provisória da República a compra da casa fosse assinalada. ${ }^{9}$ Da mesma época também datou a proposta da conversão da casa em museu, projeto que Demétrio Ribeiro apresentou ao Congresso Nacional. Já o interesse pela preservação da casa de Rui Barbosa e de sua biblioteca datam de 1923 e promoveu menor intervalo de espera entre a compra do imóvel e sua abertura enquanto museu.

A aquisição da casa de Rui Barbosa foi decorrente do projeto no 114 do Senado, apresentado em 1923 pelo senador Antônio Azeredo que sugeria a compra do imóvel com mobiliário, biblioteca, arquivo, manuscritos e obras inéditas. Entretanto, o desejo de preservação do patrimônio intelectual de Rui já se antecipava pelos procedimentos dos

\footnotetext{
${ }^{9}$ A casa em que residia Benjamin Constant e a família não era própria. O imóvel pertencia a Antônio Moreira da Costa Santos, cujas iniciais estão marcadas no gradil do balcão de um dos quartos da casa. Após a União comprá-la, a viúva Maria Joaquina e, depois, a filha solteira Araci, ainda nela residiram, por usufruto, até 1961.
} 
familiares, principalmente pelas ações de Maria Augusta, a viúva. Ela solicitou um levantamento dos títulos de todos os livros do marido, de modo a justificar a importância daquele acervo para a nação. Cada livro constou nominalmente no inventário de Rui Barbosa. Em 1924, alguns decretos permitiram abertura de crédito para a concretização do projeto $^{10}$ e segundo depoimento de João e Octavio Mangabeira, envolvidos com o projeto: "Realizada aquisição, o Governo destinará o edifício e as instalações atuais para servir de museu-biblioteca, como homenagem à memória daquele ilustre brasileiro, ou a dar o destino que julgar mais conveniente". (Mangabeira; Mangabeira, 1924: 63)

Em ambos os casos foi a ação no mundo da política, da ação pública, dos personagens Benjamin Constant e Rui Barbosa - que fez com que se pensasse em preservar suas memórias. A diferença em relação a outros projetos de construção da história da nação está na opção de escolher não coisas do mundo oficial, mas as casas em que moraram para simbolizarem sua existência, considerada de grande importância para a nação, para o âmbito da res publica. ${ }^{11}$

Não se tratava de erigir esculturas monumentais, de construir bens tangíveis, para que suas memórias encontrassem resguardo e servissem de lembretes para gerações futuras em praças, avenidas ou largos. Não bastava posterizar em esculturas públicas as imagens de Rui Barbosa e Benjamin Constant por meio da interpretação de determinado artista. Preservava-se o que era próprio de suas vidas familiares, aquilo que materialmente circundava suas vidas domésticas, privacidade, íntimo. Também não era o caso de apenas recolher objetos pessoais que dessem conta de representá-los e expô-los em vitrines ou seções de grandes museus. Eram suas casas que ocupavam o espaço do monumento, ou seja, elas se transformavam em monumento, em história, em lugar de memória.

\footnotetext{
10 Decreto n. 4.789, de 2 de janeiro de 1924, que Autoriza o Poder Executivo a adquirir a casa em que residiu, o senador Ruy Barbosa, com mobiliario, bibliotheca, archivo, etc, assinado pelo presidente Arthur Bernardes. Decreto n. 16651, de 23 de outubro de 1924, que Abre, ao Ministério da Justiça e Negócios Interiores, o crédito especial de 2.965:000\$, para pagamento em apólices da Dívida Pública Interna, das despesas com aquisição da propriedade intelectual das obras do senador Ruy Barbosa e da casa em que o mesmo residiu, nesta cidade, com a biblioteca, os manuscritos e arquivo. Os decretos podem ser acessados pelo site da Fundação Casa de Rui Barbosa, no item Sobre a Fundação e Cronologia Institucional. Disponível em: < http://www.casaruibarbosa.gov.br $>$. Acessado em janeiro de 2012.

11 Os dois acervos, que representariam seus donos, considerados heróis republicanos, foram construídos a partir do período imperial, compreendendo móveis e objetos anteriores e posteriores à República. Não cabe, assim, uma tentativa de classificar seus interiores e objetos como imperiais ou republicanos.
} 
As duas propriedades são tombadas pelo Serviço de Patrimônio Histórico e Artístico Nacional no livro de tombo de bens históricos - a casa de Rui em 11 de maio de 1938 (também inscrita no livro de belas artes) e a de Benjamin em 2 de abril de 1968. Elas foram preservadas pelo vínculo com seus antigos donos e não por um possível valor artístico dos ambientes interiores e objetos de uso, sua arte doméstica. Por mais que não fosse contemplada como valor artístico ou histórico, a arte doméstica seria a melhor representante de uma casa como ideia de memória, pois ninguém pensa em casa vazia. Pessoas moram com coisas e nos intervalos de espaço entre as coisas.

Fig.8. Gabinete de Benjamin Constant, com paredes forradas em papel, piso em tábua corrida, lustre à gás, armáriobiblioteca, escrivaninha sobreposta por caixa, castiçal com manga, porta-retrato e porta-cartões, cadeiras em madeira e palhinha. Museu Casa de Benjamin Constant. Foto Marize Malta

Após a morte de Rui Barbosa, em 1923, sem que houvesse uma ação efetiva para a manutenção dos móveis e objetos na casa, seus bens foram dispersos entre herdeiros e em leilão, evento ocorrido em 23 de dezembro de 192412. Parte dos objetos permaneceu com Maria Augusta, a viúva, que, mudando para uma casa menor no bairro de Copacabana, restringiu o número de peças com que iria conviver. Somente entre 1926 e 1930, tendo importante articulador o presidente Washington Luís ${ }^{13}$, deu-se por concluída a aquisição do imóvel, a reconstituição do terreno original e o início da recolha dos móveis e demais

\footnotetext{
12 O anúncio do leilão e o seu catálogo foram publicados no Jornal do Comércio de 21 de dezembro de 1924. 13 Decreto n. 17.758, de 4 de abril de 1927, que Crea o Museu Ruy Barbosa e approva o seu regulamento. Decreto n. 5.566, de 5 de novembro de 1928, que Autoriza o Poder Executivo a despender a quantia de 350:000\$000, para attender á acquisição do mobiliario que pertenceu a Ruy Barbosa e a despezas complementares da installação da Casa de Ruy Barbosa. Ambos assinados pelo presidente Washington Luis.
} 
objetos que comporiam a decoração da casa, para dar conta da museografia de um museucasa, o primeiro do país. Alguns itens não pertencentes a Rui foram adquiridos para montar a incipiente ambientação ${ }^{14}$. Em 13 de agosto de 1930 inaugurava-se o museubiblioteca, assim chamado porque os 37 mil livros de Rui Barbosa nunca saíram da casa, e foram o primeiro grande alvo de interesse de preservação, muitos permanecendo nos lugares designados por seu dono. A ideia de cultuar o homem público por meio de sua casa e livros se materializava.

No caso do museu-casa de Benjamin Constant foi preciso esperar um pouco mais a abertura do museu. Em 18 de outubro de 1982, o jornal Tribuna da Imprensa anunciava: "Museu vai homenagear político republicano. A Fundação Pró-Memória do MEC vai inaugurar hoje, no Rio, o novo museu Benjamin Constant, montado no próprio sobrado onde morou o republicano"15. Ao afirmar que o museu de Benjamin Constant instalava-se na casa em que o próprio havia morado, chamava-se a atenção para a situação: sua antiga casa abrigaria o seu museu ou o museu ficaria em sua própria casa.

Ao se optar por preservar as casas de dois cidadãos ilustres, referendava-se a valorização dos lugares em que passaram boa parte de suas vidas, envolvendo privacidade, intimidade, familiaridade. Casas não representavam apenas ideias em materialidades, cujos significados foram atribuídos por outras pessoas, mas continham espaços e coisas impregnadas da vivência dos moradores. Cada canto ou cada coisa possuía sentido para Rui Barbosa e para Benjamin Constant. Acreditava-se que o objeto seria evocador de lembranças, um intermediário do pensamento de seus donos.

Atribuíam-se aos espaços de vida doméstica o poder de evocar com mais fidelidade e maior facilidade o caráter dos dois ilustres brasileiros. Os espaços de trabalho ou de convivência pública, em que a impessoalidade dominava, opunham-se aos espaços da morada, impregnados com exclusividade pelas características dos moradores, sendo 'naturalmente' fiéis mediadores de suas memórias. As casas ofereciam a oportunidade de irem além dos personagens Rui Barbosa e Benjamin Constant, levando o público a conhecer o Rui e o Benjamin.

\footnotetext{
${ }^{14}$ A aquisição ou doação dos objetos que pertenceram à casa de Rui Barbosa foi fruto de um processo gradual. A mobília do quarto do casal, por exemplo, só chegou ao museu em 1952.

15 Tribuna da Imprensa, Rio de Janeiro, 18-10-1982. [Arquivo do IPHAN, Caixa 0714, pasta 2706/02, fl.269]
} 
Fazer da casa um monumento, símbolo de seus eminentes moradores, implicava assumir vários compromissos. Ao se escolher a casa como geografia de memória, era preciso apresentá-la de modo que o público a reconhecesse como tal. Haveria a necessidade de remontar todos os ambientes nos mínimos detalhes para a casa se mostrar verossímil. É bastante flagrante observarmos, por exemplo, as reportagens em jornais que anunciavam abertura ou reabertura do Museu Benjamin Constant, entre os anos de 1980 e 1990. Em praticamente todos eles a questão da reconstituição era demarcada e apontava para o quanto de confiável o público estava sendo convidado a ver. Expressões como "todos os seus ambientes reconstituídos"16, "no interior totalmente reconstituído com móveis de época"17, "remontado exatamente como no século XIX"18 nos fazem perceber que a reconstituição fazia parte de um movimento de afirmação do próprio sentido de museucasa. No folheto explicativo sobre o museu, que circulava nos primeiros anos de 2000, registrava-se que o museu-casa fora

(...) criado em 1982 pela então Secretaria do Patrimônio Histórico e Artístico Nacional e Fundação Nacional Pró-Memória com o propósito de reconstituir o ambiente familiar e o contexto sociocultural em que viveu uma das figuras de maior destaque da história republicana do país.

Portanto, caso um dito museu-casa não apresentasse imagens reconstituídas de ambientes domésticos, perderia sua razão de ser e sua autenticidade, firmadas sobre lugares e objetos autênticos, como muitos museus históricos no século XIX se propuseram (Haskell, 1993: 279-303).

O museu-casa de Rui Barbosa passou por ampla reforma nos anos 1960 e início dos anos 7019. Os papéis de parede foram trocados (Casa Davi), estofados e cortinas reformados (Libonatti), trazendo nova atmosfera à casa, aproximando-a de um universo doméstico convincente, mas sem um compromisso histórico estrito. No entanto, naquele momento, a casa não podia ser visitada e compreendida na sua totalidade, pois se usava parte do imóvel para instalação dos serviços administrativos da instituição (sobrado, área de

\footnotetext{
16 Jornal do Brasil, Rio de Janeiro, 25-05-1991.[ Arquivo do IPHAN, Caixa 0714, pasta 2706/02, fl. 289]

17 Jornal do Brasil, Rio de Janeiro, 17-01-1987, Caderno da Cidade. Coluna Serviço, p.6. [Arquivo do IPHAN, Caixa 0714, pasta 2706/02, fl. 287]

180 Globo, Rio de Janeiro, Rio Show, 24-05-1991. [Arquivo do IPHAN, Caixa 0714, pasta 2706/02, fl.288]

19 As informações acerca da história da museografia da Casa Rui foram pesquisadas pela museóloga Cláudia Barbosa Reis e reunidas em texto não publicado, datado de maio de 2007. A cópia do texto foi cedido pela museóloga, a quem muito agradeço pela gentileza.
} 
serviço e algumas outras salas). Cômodos de menos importância social, como quartos de vestir e dependências de empregados, não precisavam ser mostrados. Acreditava-se que os aposentos sociais de recebimento seriam suficientes para compreender a casa ${ }^{20}$.

A imagem da decoração das casas deveria passar uma atmosfera de harmonia, ordem, felicidade, amor, fatores considerados inerentes à família e ao lar ideais, ambos construídos no século XIX. Para isso a reconstituição dos ambientes era imprescindível quanto mais as imagens conseguissem transmitir esse paradigma, melhor transmitiriam seu discurso.

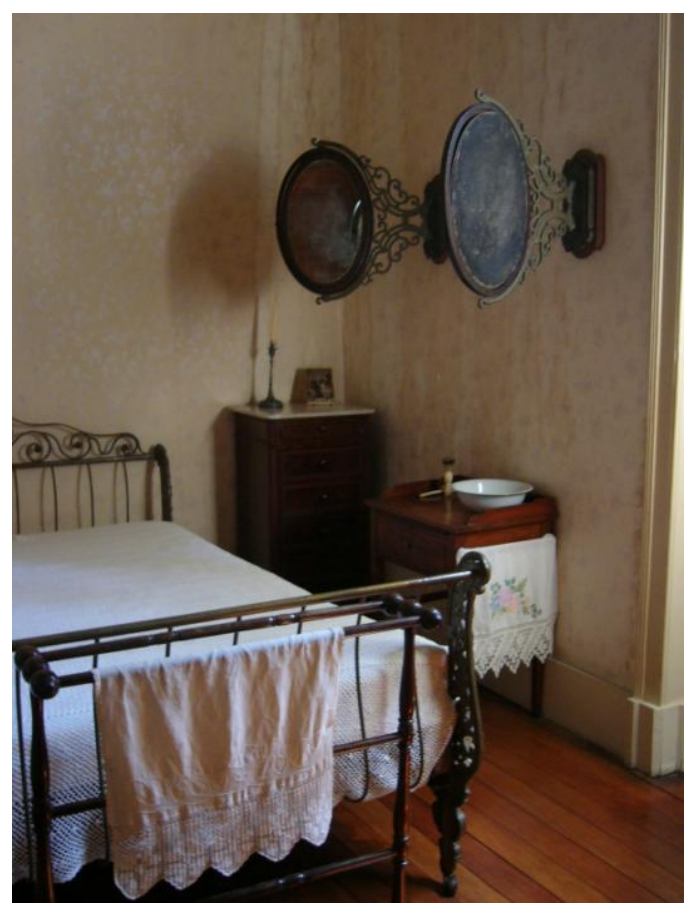

Fig.9. Dormitório do casal Maria Joaquina e Benjamin Constant, com paredes forradas em papel, piso em tábua corrida, cama em ferro, porta-toalha, criado-mudo com castiçal e porta-retrato, mesa-toalete com toalha, bacia, pincel e navalha e, assente à parede, par de espelhos para toucador. Museu Casa de Benjamin Constant. Foto Marize Malta

A mesma crença que atribuía aos quadros de gênero ou de naturezas-mortas suportes fiéis da realidade (Alpers, 1999), alcançaram as práticas museográficas e, desse modo, quanto mais naturalista a casa fosse, mais evocativa de realidade seria, mais o visitante acreditaria na presença (mesmo fantasmagórica) de seus antigos donos, mais ele se convenceria de

20 Hoje no Museu Casa de Rui Barbosa o número de cômodos acessíveis ao visitante aumentou significativamente, mesmo que ainda exista um ou outro recinto na ala de serviço que permanece fechado. Podem-se ver banheiros, cozinha, gabinete íntimo, quarto de empregada, além dos cômodos de recepção e trabalho. 
que Rui Barbosa chegaria a qualquer momento ou de que Benjamin Constant adentraria pelo seu gabinete. Como um quadro de gênero de interior doméstico ${ }^{21}$, aqueles interiores eram representações. Simulavam uma determinada realidade, construída de acordo com tempos e sujeitos envolvidos e práticas de olhar.

Certamente, para que o público pudesse usufruir dessa intimidade, a casa não podia mais ser casa. 0 que era pessoal virara público, o acervo dirigia-se ao público, a casa se transformava em um símbolo coletivo. Facilitava-se a preservação do mito através de suas fantasmagorias, além de sua própria imagem como fantasma (Evres, 1997: 221-224), pois não custa lembrar que fantasmas são presenças invisíveis e exclusivas das habitações onde moraram quando vivos.

No caso do museu de Benjamin Constant, coube basicamente à museóloga Hercília Canosa Viana empreender a árdua tarefa de transformar aqueles espaços vazios e abandonados 22 em imagens que demonstrassem não só a vida familiar de fins do século XIX, mas a vida da família Benjamin Constant. A museóloga, nos idos anos de 1970, lançou mão da memória dos familiares, visto serem praticamente inexistentes fotografias do interior da casa e documentos que servissem de indícios quanto à disposição dos móveis.

Acompanhando os ofícios enviados ao IPHAN, é possível mapear o percurso da museóloga para transformar o vazio em um convincente lugar de memória familiar dessa época - um museu-casa. Foram recolhidas peças e reunidas sob determinado arranjo para aparentarem o que teria sido a casa de Benjamin, mas, potencialmente, deveriam representar uma casa para toda a nação.

D. Hercília contou com o neto Benjamin Constant Fraenkel, que não conheceu o avô, mas viveu na casa por alguns anos, no início do século, e formou uma imagem do avô pelos relatos de parentes e amigos da família. Uma série de cartas de Benjamin Neto à museóloga, pertencentes ao arquivo do museu, oferece as pistas de suas memórias e de onde certas escolhas museológicas se basearam. Há até desenhos rabiscados de objetos, elementos arquitetônicos, arranjos de móveis, alguns dos quais serviram até como modelo para reproduções.

\footnotetext{
21 A respeito da relação entre as representações dos interiores domésticos em pintura e a pintura nos interiores domésticos em fins do século XIX (Malta, 2011b: 867-873).

220 imóvel foi devolvido ao Estado em 1961, após morte de Aracy, filha solteira de Benjamin Constant, mas somente na década seguinte se iniciaram os trabalhos para transformar a casa em museu.
} 
Peças foram doadas, paulatinamente, pelos herdeiros. A casa, assim, é também resultado da vontade dos herdeiros em ver preservada a memória de seu antecessor. A própria museóloga foi doadora de peças para compor a reconstituição dos ambientes da casa de Benjamin Constant, como cadeiras, armário, garrafas, limpa-pés, que constam nas fichas museográficas e documentos dos arquivos do museu.

Fig.10. Quarto de costura, com paredes forradas em papel, piso em tábua corrida, baú sobre pedestais, estante em ferro e madeira, mesa com máquina de costura, cadeiras, armário, tela com moldura dourada e arandela em vidro. Museu Casa de Benjamin Constant. Foto Marize Malta

Ao inserir objetos domésticos em museus, novas imagens eram construídas, de modo que outros significados lhes fossem atribuídos. Seu sentido doméstico se coletivizava, sua inserção decorativa se transformava. Os móveis, os objetos e seus arranjos transformavam-se em novos documentos, pois eram

(...) antes de mais nada o resultado de uma montagem, consciente ou inconsciente, da história, da época, da sociedade que o produziram, mas também das épocas sucessivas durantes as quais continuou a viver, talvez esquecido, durante as quais continuou a ser manipulado, ainda que pelo silêncio. (Le Goff, 1996: 547) 
Tanto no museu-casa de Benajmin Constant quanto no de Rui Barbosa, cada geração de museólogos recebeu peças de doadores ou descendentes, recuperou revestimentos antigos, vestiu os espaços, permitindo reinventar a autenticidade do acervo e reforçar a veracidade do lugar. Novas decorações eram propostas a partir das recentes aquisições, das necessidades de preservação, dos conceitos museológicos, reinventando a arte doméstica do passado.

A combinação de coisas certas nos ambientes condizentes não é nada fácil de se encontrar. Tal qual uma boa peça teatral, a museografia de um museu-casa dramatiza uma história imaginada e cada geração escreve a sua versão da história, procurando convencer de suas verdades. Se cada geração do passado desenvolveu sua idealização de casa e toda casa muda com o tempo, a arte doméstica constrói-se na mobilidade, na natureza modificante da orquestração de objetos, revestimentos e sensações promovidas pelo conjunto em disposição.

A natureza instável do museu-casa, ao mesmo tempo que se aproxima das práticas vividas, dificulta encarar a arte doméstica como uma produção artística e cultural digna de figurar nos livros de arte. Não se sabe o autor da obra (a decoração da casa foi feita a muitas mãos) e a obra (os ambientes interiores com coisas) se reinventa e se modifica conforme os tempos, desestabilizando uma pretensa autenticidade que a legitimaria na seara da tradicional história da arte. Ao mesmo tempo, cada intervenção realizada nos museuscasa de Rui Barbosa e de Benjamin Constant atualizou seus espaços e aparências, aproximando-os das expectativas dos visitante, de uma recepção coletiva. Se, para os céticos, aquela arte doméstica remodelada se distanciava da casa 'original' desses homens notáveis, ela se aproximava de uma imagem de nação. As ambiências se fizeram com objetos 'autênticos', que pertenceram aos patronos dos museus, e outros de diversas procedências, sendo conformados e dispostos por intenções de pessoas e épocas distintas, constituindo-se como obra coletiva e, como tal, predisposta a se constituir como representante da nação. Assim, a arte doméstica encontrada nos museus-casa de Rui Barbosa e de Benjamin Constant é imagem-síntese de tempos e espaços e nela cada um de nós pode se ver espelhado. Passeando pelos cômodos do museu, podemos até distraidamente dizer: "Entre, que a casa é sua!" 


\section{REFERÊNCIAS}

ABREU, Regina. A fabricação do imortal. Rio de Janeiro: Rocco: Lapa, 1996.

ALPERS, Svetlana. A arte de descrever; a arte holandesa do século XVII. São Paulo: EdUSP, 1999.

COHEN, Debora. Household gods: the british and their possessions. New Haven/ London: Yale University Press, 2006.

CHAGAS, Mário de Sousa Chagas. O museu-casa como problema: comunicação e educação em processo. Seminário sobre museus-casa, Rio de Janeiro, 1997, p.177-199.

EVRES, Ana Cristina. Museu-casa, museu-templo - quando o mito vira fantasma na Casa de Benjamin Constant. In: SEMINÁRIO SOBRE MUSEUS-CASAS, 1., 1995, Rio de Janeiro. Anais... Rio de Janeiro: FCRB, 1997.

GASKELL, Ivan. História das imagens. In: BURKE, Peter (org.). A escrita da história: novas perspectivas. São Paulo: UNESP, 1992.

GUIA DOS MUSEUS BRASILEIROS. Brasília: Instituto Brasileiro de Museus, 2011.

HALBWACHS, M. A memória coletiva. São Paulo: Vertice, 1990.

HASKELL, Francis. Museums, illustrations and the search for authenticity. In: History and its images: art and the interpretation of the past. New haven: London: Yale University Press, 1993.

JONES, Robin D. Interiors of Empire: objects, space and identity within the indian subcontinent, c.1800-1947. Manchester: Manchester University Press, 2007.

KNAUSS, Paulo. "O cavalete e a paleta: a arte de colecionar no Brasil". Anais do Museu Histórico Nacional, vol. 33. Rio de Janeiro: O Museu, 2001.

LE GOFF, Jacques. História e memória. São Paulo: Editora da UNICAMP, 1996. p.547

MALTA, Marize. O olhar decorativo: ambientes domésticos em fins do século XIX no Rio de Janeiro. Rio de Janeiro: Mauad X/Faperj, 2011a.

Imagens atrás da porta: a arte na domesticidade e a domesticidade na arte finissecular. In: COLÓQUIO DO COMITÊ BRASILEIRO DE HISTÓRIA DA ARTE, 30., 2010, Rio de Janeiro. Anais... Rio de Janeiro: CBHA/Uerj, 2011b.

MANGABEIRA, João; MANGABEIRA, Octavio. Sobre Ruy Barbosa - um discurso e um parecer. Rio de Janeiro: edição dos autores, 1924.

MENESES, Ulpiano T. Bezerra de. Do teatro da memória ao laboratório da história. A exposição museológica e o conhecimento histórico. Anais do Museu Paulista. História e Cultura Material (São Paulo), n.sér., n.3, p.9-42 e 75-84, 1994.

NORA, Pierre. Entre mémoire et histoire: la problematique des lieux. In: GERON, Charles-Robert. (org). Le lieux de mémoire. Paris: Gallimard, 1984. V.2. La Nation.

WILDE, Oscar. The true function and value of criticism. In: DRAKE, Alfred. Victorian prose archive. Irvine: University of Califórnia, 2002. Disponível em: http://www.victorianprose.org.

Artigo recebido em janeiro de 2012. Aprovado em março de 2012 